$11-3-2014$

\title{
Risk and Protective Factors associated with Personal Mastery among Sexual Minority African-American Female Sex Workers
}

\author{
Mance E. Buttram \\ Nova Southeastern University, mance.buttram@nova.edu \\ Hilary L. Surratt \\ Nova Southeastern University, surratt@nova.edu \\ Steven P. Kurtz \\ Nova Southeastern University, steven.kurtz@nova.edu
}

Follow this and additional works at: https://nsuworks.nova.edu/shss_facarticles

Part of the Medicine and Health Sciences Commons, and the Sociology Commons

\section{NSUWorks Citation}

Buttram, M. E., Surratt, H. L., \& Kurtz, S. P. (2014). Risk and Protective Factors associated with Personal Mastery among Sexual Minority African-American Female Sex Workers. Journal of Gay \& Lesbian Social Services, 26 (4), 407-425. https://doi.org/10.1080/10538720.2014.956242

This Article is brought to you for free and open access by the Faculty Scholarship at NSUWorks. It has been accepted for inclusion in CAHSS Faculty Articles by an authorized administrator of NSUWorks. For more information, please contact nsuworks@nova.edu. 


\title{
Risk and Protective Factors Associated with Personal Mastery Among Sexual Minority African- American Female Sex Workers
}

\author{
Mance E. Buttram, Hilary L. Surratt \& Steven P. Kurtz
}

To cite this article: Mance E. Buttram, Hilary L. Surratt \& Steven P. Kurtz (2014) Risk and Protective Factors Associated with Personal Mastery Among Sexual Minority AfricanAmerican Female Sex Workers, Journal of Gay \& Lesbian Social Services, 26:4, 407-425, DOI: 10.1080/10538720.2014.956242

To link to this article: https://doi.org/10.1080/10538720.2014.956242

曲 Published online: 03 Nov 2014.

Submit your article to this journal $\sqsubset$

Џll Article views: 249

View related articles $\sqsubset$

View Crossmark data \lceil

Citing articles: 4 View citing articles 주 


\title{
Risk and Protective Factors Associated with Personal Mastery Among Sexual Minority African-American Female Sex Workers
}

\author{
MANCE E. BUTTRAM, HILARY L. SURRATT, and STEVEN P. KURTZ \\ Nova Southeastern University, Miami, Florida, USA
}

\begin{abstract}
Research among sexual minorities has traditionally examined problems such as substance use, HIV risk, mental health problems, and victimization. Among sexual minority street-based female sex workers, these vulnerabilities can be magnified. Grounded in theories of resilience, this study examines risk and protective factors associated with a high level of personal mastery among a vulnerable population of women. Data are drawn from baseline interviews from street-based African-American female sex workers enrolled in a randomized intervention trial in Miami, Florida. We compare sexual minority $(\mathrm{N}=197)$ and heterosexual $(\mathrm{N}=365)$ women on measures of risk and protective factors; among sexual minority women we present logistic regression analyses which reveal that severe mental distress and HIV transmission risk are associated with low levels of personal mastery, while protective factors of transportation access and social support are associated with high levels of personal mastery. These findings suggest that these protective factors may potentially facilitate the development of personal mastery and represent beneficial avenues for intervention efforts.
\end{abstract}

KEYWORDS personal mastery, African-American, sexual minority, sex work

\section{INTRODUCTION}

By all accounts, street-based female sex workers in the United States constitute an especially vulnerable population as they are often enmeshed in

Address correspondence to Mance E. Buttram, ARSH: Center for Applied Research on Substance Use and Health Disparities, Nova Southeastern University, 2 NE 40th Street, Ste. 404, Miami, FL 33137. E-mail: mance.buttram@nova.edu 
chronic patterns of substance use, sexual risk, mental distress, victimization, and homelessness (Baseman, Ross, \& Williams, 1999; Davis, 2000; Gilbert, El-Bassel, Rajah, Foleno, \& Frye, 2001; Inciardi \& Surratt, 2001; Kurtz, Surratt, Inciardi, \& Kiley, 2004; Surratt \& Inciardi, 2004; Surratt, Kurtz, Weaver, \& Inciardi, 2005; Wenzel, Leake, \& Gelberg, 2001). Street-based sex workers or exchangers are embedded in a complex of social situations that make them an important population to reach with health and social services. Significant numbers have histories of childhood sexual and physical abuse, increasing their susceptibility to mental and emotional problems (El-Bassel, Simoni, Cooper, Gilbert, \& Schilling, 2001; Farley \& Barkan, 1998; Gidycz, Coble, Latham, \& Layman, 1993; Maher, 1997; Sterk \& Elifson, 1990). Furthermore, violent victimization at the hands of "dates" (clients or "johns"), boyfriends, and other predators, such as people living on the streets, passersby, or the police, continues to play a large role in their adult lives (Church, Henderson, Barnard, \& Hart, 2001; Coston \& Ross, 1998; Farley \& Barkan, 1998; Kurtz et al., 2004; Surratt, Inciardi, Kurtz, \& Kiley, 2004). At the same time, they are at high risk for loss of social services and social support structures, including family, church (Dalla, 2001; Weiner, 1996), and stable housing (Spittal et al., 2003). In fact, many of these health and social disparities are multiple and co-occurring among populations of female sex workers (Carlson et al., 2012; Romero-Daza, Weeks, \& Singer, 2003; Romero-Daza, Weeks, \& Singer, 2005; Shannon \& Csete, 2010; Shannon et al., 2008; Sterk \& Elifson, 2006).

A variety of studies have shown that sexual minority women experience many of the same health disparities as female sex workers, such as higher rates of victimization, problematic substance use, sexual risk, and psychological distress, compared to their heterosexual counterparts (Bell, Ompad, \& Sherman, 2006; Cochran, Ackerman, Mays, \& Ross, 2004; Drabble \& Trocki, 2005; Tucker, Ellickson, \& Klein, 2008). Specifically, women who report same-sex behaviors or identify as either lesbian or bisexual are more likely to be heavy alcohol users (Drabble, Midanik, \& Trocki, 2005; Meads, Buckley, \& Sanderson, 2007), more likely to report tobacco and illicit drug use, and more likely to have histories of injection drug use (Burgess, Lee, Tran, \& Van Ryn, 2008; Hillier, De Visser, Kavanagh, \& McNair, 2003; Lindley, Barnett, \& Burcin, 2008; McCabe, Hughes, \& Boyd, 2004; Meads et al., 2007; Saulnier \& Miller, 1997). Sexual risk also tends to be elevated among sexual minority women, with some reports indicating higher numbers of current sexual partners, and more unprotected and transactional sex than among heterosexual women (Austin et al., 2008; Bell et al., 2006). Sexual minority women also tend to display elevated rates of psychological distress, including anxiety and depression (Burgess et al., 2008; Wilsnack et al., 2008). It has been widely noted that the poorer mental health functioning observed among sexual minorities is likely grounded in experiences of discrimination and victimization, as well as lower social support, family rejection, and 
marginalization (Corliss, Austin, Roberts, \& Molnar, 2009; Mayer et al., 2008; Ryan, Huebner, Diaz, \& Sanchez, 2009).

Though many health and social disparities are well-documented among female sex workers and sexual minority women, the ability to seek out resources for support, engage in successful coping, or utilize other protective factors in the face of risk or adversity are hallmarks of resilience (Obrist, Pfeiffer, \& Henly, 2010; Ungar, 2008). There are no apparent studies of resilience among sexual minority female sex workers; yet evidence shows that stressful events can lead to positive growth and coping behaviors among sexual minority women, and especially sexual minority women of color (Bonet, Wells, \& Parsons, 2007; Balsam, 2003). While such resilient behaviors have not been well-studied among street-based female sex workers in the United States, international research with female sex workers indicates that better health outcomes are associated with protective factors such as self-efficacy (Ghimire, Smith, van Teijlingen, Dahal, \& Luitel, 2011; Guha et al., 2012) and that HIV prevention efforts may be more effective if education, health care, and social support services are made available (Scheibe, Drame, \& Shannon, 2012; Li et al., 2010). As a result, researchers have recently advocated resilience-based interventions for HIV prevention and psychological functioning among female sex workers in China (Yuen et al., 2013).

Within this context, this article investigates resilience among a sample of street-based African-American female sex workers in Miami, Florida. First, we examine measures of risk and protective factors, comparing sexual minority and heterosexual women. Next, we conduct logistic regression analyses to examine which risk and protective factors are associated with resilience among a sample of sexual minority African-American women in the context of a sex-work environment. In particular, we sought to understand the contributions of risk factors, such as substance use, victimization, mental health problems, and HIV risk, and protective factors, including education, health care, transportation, and social support, to the expression of resilience, as measured by personal mastery. The aim of these analyses is to uncover potential avenues of intervention for this vulnerable population.

\section{METHODS}

The data were drawn from a randomized clinical trial designed to test the relative effectiveness of two case management intervention protocols in linking underserved women with health and social services and reducing risk behaviors for HIV. Study enrollment began in May 2007 and concluded in June 2010. Overall, 562 eligible clients were enrolled into the study and completed baseline interviews. 


\section{Target Population and Study Eligibility}

The target population for this intervention trial was drug-using AfricanAmerican female sex workers in Miami, Florida. Study inclusion was limited to African-American women based on prior studies with sex workers in the Miami area, which indicated that African-Americans were two times more likely than sex workers of other race/ethnic groups to test HIV positive (Surratt et al., 2005). Eligible clients were African-American women ages 18 to 50 who had (1) traded sex for money or drugs at least 3 times in the past 30 days and (2) used cocaine, crack, or heroin 3 or more times a week in the past 30 days.

\section{Study Recruitment}

Participants in the study were recruited using targeted sampling strategies (Waters \& Biernacki, 1989). Recruitment was carried out by a team comprised of both professional outreach workers and active sex workers. The outreach staff was indigenous to the target recruitment areas, and several members of the team had prior experience conducting outreach for local community service agencies. In addition, the use of active sex workers as recruiters provided access to many locations on and off the primary strolls (locations where female sex workers solicit clients) where potential participants were found.

During the recruitment process, women who were interested in participating in the study were asked to call the field office and screen for eligibility. In total, 1,889 women participated in a telephone screening, of which 837 were eligible. A total of 562 women ultimately participated in the study. Reasons why eligible women did not participate included not being interested or not coming to the baseline visit.

\section{Study Procedures}

Study recruiters made contact with potential participants in various street locations. Potential participants were asked to contact the field office for telephone screening for eligibility. Those meeting project eligibility requirements were scheduled for appointments at the project intervention center, where they were re-screened on arrival. After eligibility was confirmed, informed consent was obtained, followed by a structured face-to-face baseline interview lasting approximately one hour. Project staff completed the requirements for National Institutes of Health (NIH) Web-based certification for protection of human subjects. Study protocols were approved by the University of Delaware (predecessor institution) and Nova Southeastern University Institutional Review Boards. 


\section{DATA COLLECTION AND MEASURES}

Interviews were conducted using computer-assisted personal interviews (CAPI). The Global Appraisal of Individual Needs (GAIN, v. 5.4; Dennis, Titus, White, Unsicker, \& Hodgkins,2002) was the primary component of the standardized baseline assessment. This instrument captured demographic information, physical and mental health status, homelessness, foster care history, violence and victimization, as well as lifetime and 90-day measures of drug use frequency and sexual risk behaviors.

\section{Sexual Orientation}

Sexual orientation was assessed with the closed-ended question, "Do you consider yourself to be ...?" For analyses, the responses of "lesbian," "bisexual," or "other" were categorized as "sexual minority," while responses of "heterosexual" or "straight" were categorized as heterosexual. Although we recognize that sexual identity is multidimensional, incorporating cognitive, emotional, and behavioral aspects, we chose to examine sexual minority membership as defined by lesbian, bisexual, or transgender identification. Other analyses, typically those with a public health focus, tend to emphasize behavioral aspects of sexuality. While there is some dispute among researchers regarding the appropriateness of examining cognitive versus behavioral aspects of sexuality (Young \& Meyer, 2005; Ford, 2006; Pathela, Blank, Sell, \& Schillinger, 2006), and recognition that concordance between identity and behavior varies (Ross, Essien, Williams, \& Fernandez-Esquer, 2003), our decision to focus on cognitive aspects of sexual identity was driven by the fact that, among female sex workers, sexual behaviors and partnering are often not matters of preference, but of economics and survival (Shannon et al., 2008; Inciardi, 1995).

\section{Risk Factors}

The GAIN (Dennis et al., 2002) contains the General Mental Distress Scale, consisting of clinical measures of mental health based on Diagnostic and Statistical Manual of Mental Disorders (DSM-IV) symptom criteria: 9 items assess past-year symptoms of depression, 4 items assess somatic disorders, and 12 items assess past-year symptoms of anxiety disorders (Bohlig \& Dennis, 1996; Dennis, Chan, \& Funk, 2006). Consistent with the aim of our analysis to uncover potential avenues for intervention, we dichotomized mental distress into "severe" and "not severe," the rationale being that a classification of "severe" distress most likely identifies individuals with a high probability of clinical diagnosis who are in need of 
formal intervention (Dennis et al., 2006). Cronbach's alpha for this scale in the current sample was .868 and has been reported elsewhere as .97 (Dennis et al., 2006). Examples of questions include, "During the past 12 months, have you had significant problems with feeling very trapped, lonely, sad, blue, depressed, or hopeless about the future?" and "During the past 12 months have you had significant problems with feeling very anxious, nervous, tense, scared, panicked, or like something bad was going to happen?"

Substance dependence was measured using the TCU Drug Screen II (Institute of Behavioral Research [IBR], 2006). Comprised of nine items measuring past-year drug use severity, endorsement of three or more items approximates DSM-IV criteria for dependence. Cronbach's alpha for this measure in the current sample was .8 and has been reported elsewhere as .89 (Simpson, Joe, Knight, Rowan-Szal, \& Gray, 2010). Examples of questions include, "During the last 12 months did you use larger amounts of drugs or use them for a longer time than you meant to?" and "During the last 12 months did you get so high or sick from drugs that it caused an accident or put you or others in danger?"

The GAIN (Dennis et al., 2002) contains the General Victimization Scale (GVS), which is a 15-item measure of types of victimization experienced by the respondent (including lifetime physical, emotional, and sexual victimization), the number of traumagenic factors involved in the victimization (including age at onset, duration, type, and relation of perpetrator), and current worry about victimization. Cronbach's alpha of GVS in this sample was .717 and has been reported elsewhere as .86 (Titus, Dennis, White, Scott, \& Funk, 2003). Examples of questions include, "Has anyone ever hurt you by striking or beating you to the point that you had bruises, cuts, broken bones, or otherwise physically abused you?" and "Has anyone ever forced you to participate in sexual acts against your will, including a regular sexual partner, a family member, or friend?" Given the pervasive violence in the street-based sex-work context (Kurtz et al., 2004; Surratt \& Inciardi, 2010; Surratt, Kurtz, Chen, \& Mooss, 2011), we chose to exclude the four "current worry" items in our instrumentation, as they were likely to be universally endorsed. As such, our GVS scale consists of 11 items in total. Higher values indicate increased victimization and/or increased traumatic factors associated with the victimization. For analysis, the measure was dichotomized into "severe" (endorsement of four or more symptoms) and "not severe."

HIV risk was measured by asking clients to report counts of past-90-day vaginal and anal sex times as well as counts of the number of vaginal and anal sex times in which a condom was used. The measure was dichotomized so that HIV risk was defined as one or more unprotected vaginal or anal sex times versus none. 


\section{Protective Factors}

Health care coverage was assessed by asking clients if their medical expenses were covered by any type of insurance, court, or health program. Transportation access was selected as a protective factor because prior research among this population suggested that this resource is lacking and that having it would make engaging with health and social services less burdensome (Kurtz, Surratt, Kiley, \& Inciardi, 2005). This measure was assessed by asking clients to identify their most common form of transportation. Clients who reported using their personal vehicle or using public transportation were categorized as having "more access," while clients reporting walking, biking, or depending on rides from others for the primary mode of transportation were categorized as "less access."

Social support was measured using the 19-item MOS Social Support Survey (Sherbourne \& Stewart, 1991), which includes the domains of emotional/informational support, tangible support, affectionate support, and positive social interaction. Scores were calculated according to the scale's authors' guidelines, and were transformed to a 0-100 scale for comparison to published means. Cronbach's alpha for overall social support in this sample was .966 and has been reported elsewhere as .91 (Sherbourne \& Stewart, 1991). Examples of questions include, "How often is it that you have someone you can count on to listen to you when you need to talk?" and "How often is it that you have someone who hugs you?"

\section{Resilience}

Personal mastery (Pearlin \& Schooler, 1978) measures the extent to which an individual believes life events or circumstances are under one's own control. It is a widely used measure consisting of 7 items, answered on a 5-point scale, which has been shown to have good internal reliability (Seeman, 1991) and construct validity (Pearlin, Menaghan, Lieberman, \& Mullan,1981). Cronbach's alpha for personal mastery in the current sample was .561 and has been reported elsewhere as .75 (Scheier, Carver, \& Bridges, 1994). Respondents are asked to agree or to disagree with statements such as, "There is really no way I can solve some of the problems I have," and "I can do just about anything I really set my mind to."

Recent studies have used personal mastery as a measure of resilience (Harmell, Chattillion, Roepke, \& Mausbach, 2011), and as a coping resource, personal mastery is associated with improved mental and physical health, reduced risk of mortality, and reduced impact of chronic stress on disease (Roepke \& Grant, 2011). Furthermore, additional reports have shown that higher personal mastery is associated with better health outcomes and stronger increases in social support (Gerstorf, Röcke, \& Lachman, 2011). For 
analysis, this scale was used as a proxy for resilience based on the idea that the development of personal mastery is preceded by the cultivation of successful coping or other means of overcoming risk and is a product of these efforts (Younger, 1991). The range of the scale for this study was 11-35; higher scores represent higher personal mastery. For analysis, the measure was dichotomized at the sixty-sixth percentile with high personal mastery defined as the upper 33.3\% versus low personal mastery (lower twothirds).

\section{ANALYTIC PLAN}

All analyses were conducted using IBM SPSS Statistics version 20. Descriptive statistics were calculated for the variables of interest, including demographics, risk factors, protective factors, and personal mastery by sexual minority identity. We hypothesized that high personal mastery would be associated with lower levels of risk factors and higher levels of protective factors. Bivariate logistic regression models were constructed to predict high levels of personal mastery by these risk and protective factors. Those measures that exhibited significant associations in the bivariate models were included in a multivariate logistic regression model, with the aim of the analyses being to focus on risk and protective factors that could be intervened upon to help these women. As a result, HIV status and foster care history were not included in the multivariate analyses.

\section{RESULTS}

Selected characteristics of the sample are shown in Table 1 . The sample was $35.1 \%$ sexual minority $(N=197)$ and $64.9 \%$ heterosexual $(N=365)$. Mean age for sexual minority women was $36.56(S D=9.31)$ compared to 39.26 ( $S D=8.50)$ for heterosexual women $(p<0.000)$. Sexual minority women reported greater prevalence of risk factors compared to their heterosexual counterparts, including past-90-day homelessness $(64.0 \%$ versus $49.9 \% ; p=0.001)$; severe mental distress ( $84.3 \%$ versus $75.9 \% ; p=0.020$ ), and severe victimization $(87.8 \%$ versus $80.8 \% ; p=0.034)$. No significant differences were found among protective factor measures, including social support, which was similar for sexual minority women, $52.60(S D=29.41)$ and for heterosexual women, $56.86(S D=28.69 ; p=0.122)$; however, only $27.4 \%$ of sexual minority women endorsed the criteria for high personal mastery $(N=54)$ compared to $36.4 \%$ of heterosexual women $(N=133 ; p=$ 0.030).

Based on the elevated levels of risk factors among sexual minority women, bivariate logistic regression models were constructed to examine 
TABLE 1 Selected Characteristics of Street-Based African-American Female Sex Workers $(N=562)$

\begin{tabular}{|c|c|c|c|c|c|c|}
\hline \multirow[b]{2}{*}{ Characteristic } & \multicolumn{2}{|c|}{ Sexual Minority } & \multicolumn{2}{|c|}{ Heterosexual } & \multirow[b]{2}{*}{ Chi-square } & \multirow[b]{2}{*}{$p$} \\
\hline & $N=197$ & $35.1 \%$ & $N=365$ & $64.9 \%$ & & \\
\hline \multicolumn{7}{|l|}{ Demographics } \\
\hline HIV positive & 32 & $16.2 \%$ & 66 & $18.1 \%$ & 0.300 & 0.584 \\
\hline $\begin{array}{l}\text { Foster care } \\
\text { history }\end{array}$ & 41 & $20.8 \%$ & 55 & $15.1 \%$ & 2.98 & 0.084 \\
\hline \multicolumn{7}{|l|}{ Risk Factors } \\
\hline $\begin{array}{l}\text { Homeless (past } \\
90 \text { days) }\end{array}$ & 126 & $64.0 \%$ & 182 & $49.9 \%$ & 10.264 & 0.001 \\
\hline $\begin{array}{l}\text { Severe mental } \\
\text { distress }\end{array}$ & 166 & $84.3 \%$ & 277 & $75.9 \%$ & 5.375 & 0.020 \\
\hline $\begin{array}{l}\text { Substance } \\
\text { dependence }\end{array}$ & 179 & $90.9 \%$ & 322 & $88.2 \%$ & 0.924 & 0.336 \\
\hline $\begin{array}{l}\text { Severe } \\
\text { victimization }\end{array}$ & 173 & $87.8 \%$ & 295 & $80.8 \%$ & 4.495 & 0.034 \\
\hline HIV risk & 98 & $49.7 \%$ & 184 & $50.4 \%$ & 0.023 & 0.880 \\
\hline \multicolumn{7}{|l|}{ Protective Factors } \\
\hline $\begin{array}{l}\text { Education- } \\
12 \text { years or } \\
\text { more }\end{array}$ & 93 & $47.2 \%$ & 177 & $48.5 \%$ & 0.085 & 0.771 \\
\hline $\begin{array}{l}\text { Health care } \\
\text { coverage }\end{array}$ & 66 & $33.5 \%$ & 120 & $32.9 \%$ & 0.023 & 0.880 \\
\hline $\begin{array}{l}\text { More access to } \\
\text { transportation }\end{array}$ & 134 & $68.0 \%$ & 250 & $68.5 \%$ & 0.013 & 0.908 \\
\hline \multicolumn{7}{|l|}{ Resilience } \\
\hline $\begin{array}{l}\text { Personal } \\
\text { mastery (66th } \\
\text { percentile) }\end{array}$ & 54 & $27.4 \%$ & 133 & $36.4 \%$ & 4.696 & 0.030 \\
\hline
\end{tabular}

high personal mastery by risk and protective factors among this population. These analyses are based on the hypothesis that high personal mastery would be associated with lower levels of risk factors and higher levels of protective factors. Results are shown in Table 2.

Past-90-day homelessness $(\mathrm{OR}=0.444 ; 95 \% \mathrm{CI}=0.234,0.844 ; p=$ 0.013), severe mental distress ( $\mathrm{OR}=0.118 ; 95 \% \mathrm{CI}=0.051,0.275 ; p<$ $0.000)$, and HIV risk ( $\mathrm{OR}=0.440 ; 95 \% \mathrm{CI}=0.230,0.841 ; p=0.013)$ were associated with lower odds of having high personal mastery. Transportation access $(\mathrm{OR}=2.591 ; 95 \% \mathrm{CI}=1.205,5.573 ; p=0.015)$ and greater social support $(\mathrm{OR}=1.025 ; 95 \% \mathrm{CI}=1.013,1.038 ; p<0.000)$ were associated with higher odds of high personal mastery.

Measures that exhibited significant bivariate associations were included in a multivariate logistic regression model, with the aim of identifying risk and protective factors as potential avenues for intervention. Table 3 shows the results of the multivariate logistic regression model predicting a high level of personal mastery among African-American sexual minority female sex workers. Two risk factors, severe mental distress $(\mathrm{OR}=0.146 ; 95 \%$ 
TABLE 2 Bivariate Logistic Regression Models Predicting High Levels of Personal Mastery among African-American Sexual Minority Female Sex Workers $(N=197)$

\begin{tabular}{|c|c|c|c|}
\hline Characteristic & OR & $95 \% \mathrm{CI}$ & $p$ \\
\hline \multicolumn{4}{|l|}{ Demographics } \\
\hline HIV positive & 2.431 & {$[1.110,5.323]$} & 0.026 \\
\hline $\begin{array}{l}\text { Foster care } \\
\text { history }\end{array}$ & 0.303 & {$[0.112,0.820]$} & 0.019 \\
\hline \multicolumn{4}{|l|}{ Risk Factors } \\
\hline $\begin{array}{l}\text { Homeless (past } \\
90 \text { days) }\end{array}$ & 0.444 & {$[0.234,0.844]$} & 0.013 \\
\hline $\begin{array}{l}\text { Severe mental } \\
\text { distress }\end{array}$ & 0.118 & {$[0.051,0.275]$} & 0.000 \\
\hline $\begin{array}{l}\text { Substance } \\
\text { dependence }\end{array}$ & 0.980 & {$[0.332,2.893]$} & 0.971 \\
\hline $\begin{array}{l}\text { Severe } \\
\text { victimization }\end{array}$ & 0.906 & {$[0.353,2.323]$} & 0.837 \\
\hline HIV risk & 0.440 & {$[0.230,0.841]$} & 0.013 \\
\hline \multicolumn{4}{|l|}{ Protective Factors } \\
\hline $\begin{array}{l}\text { Education- } \\
12 \text { years or } \\
\text { more }\end{array}$ & 1.167 & {$[0.623,2.183]$} & 0.630 \\
\hline $\begin{array}{l}\text { Health care } \\
\text { coverage }\end{array}$ & 1.725 & {$[0.903,3.295]$} & 0.098 \\
\hline $\begin{array}{l}\text { More access to } \\
\text { transportation }\end{array}$ & 2.591 & {$[1.205,5.573]$} & 0.015 \\
\hline Social support & 1.025 & {$[1.013,1.038]$} & 0.000 \\
\hline
\end{tabular}

$\mathrm{CI}=0.057,0.378 ; p<0.000)$ and $\mathrm{HIV}$ risk $(\mathrm{OR}=0.455 ; 95 \% \mathrm{CI}=$ $0.218,0.952 ; p=0.037$ ), remained associated with lower odds of having high personal mastery. The protective factors associated with high personal mastery were transportation access $(\mathrm{OR}=2.570 ; 95 \% \mathrm{CI}=1.040,6.352$; $p=0.041)$ and greater social support $(\mathrm{OR}=1.021 ; 95 \% \mathrm{CI}=1.007,1.036$; $p=0.003)$.

TABLE 3 Multivariate Logistic Regression Models Predicting High Levels of Personal Mastery among African-American Sexual Minority Female Sex Workers $(N=197)$

\begin{tabular}{lccc}
\hline Characteristic & OR & $95 \%$ CI & $p$ \\
\hline Risk Factors & & & \\
$\quad \begin{array}{l}\text { Homeless } \\
\text { Severe mental } \\
\text { distress }\end{array}$ & 1.249 & {$[0.546,2.853]$} & 0.598 \\
$\begin{array}{l}\text { HIV risk } \\
\text { Protective Factors }\end{array}$ & 0.146 & {$[0.057,0.378]$} & 0.000 \\
$\begin{array}{c}\text { Transportation } \\
\text { access }\end{array}$ & 0.455 & {$[0.218,0.952]$} & 0.037 \\
Social support & 2.570 & {$[1.040,6.352]$} & 0.041 \\
\hline
\end{tabular}




\section{DISCUSSION AND CONCLUSION}

Findings from this study document the presence of personal mastery, and associated protective factors among a sample of African-American sexual minority street-based female sex workers. All of the women in our sample, regardless of sexual identity, reported high levels of risk including recent homelessness, severe mental distress, substance dependence, severe victimization, and HIV risk. However, a significantly higher percentage of sexual minority women reported recent homelessness and met criteria for severe mental distress and severe victimization than heterosexual women. In addition, fewer sexual minority women reported high personal mastery.

Given the prevalence of risk among female sex workers, our analysis focused on sexual minority women, who appeared to be the most vulnerable women in this African-American sample. The present study contributes to previous examinations of female sex workers and sexual minority women by demonstrating that in spite of multiple risk factors, many women express feelings of control which are related to lower levels of risk. While previous research has demonstrated that sexual minority women demonstrate resilient behavior as a means of coping with trauma or stress (Bonet et al., 2007; Balsam, 2003), ours is the first study to examine personal mastery among such a vulnerable population of sexual minority women. As such, this approach reveals the way in which protective factors influence personal mastery and contributes to the study of resilient behaviors.

The overall pattern of results was that risk factors are negatively associated with high levels of personal mastery, while protective factors have a positive association. This is consistent with recent literature that has used a resilience framework to examine health disparities and outcomes (Moskowitz, 2010; Obrist et al., 2010; Pargament \& Cummings, 2010). However, ours is the only study to employ this perspective among this vulnerable population of African-American sexual minority women, and it extends the research focused on similar drug-using female sex worker populations in the United States.

Health and social disparities due to structural inequality in access to social, educational, or material resources among African-American and streetlevel sex worker populations are well-documented (Baer, Singer, \& Susser, 1997; Romero-Daza et al., 2003; Romero-Daza et al., 2005). Our results identify specific targets for intervention at the individual level to assist sexual minority female sex workers in coping with risk factors and achieving better health outcomes. Protective factors, such as transportation access or social support, could potentially facilitate the development of personal mastery and represent beneficial avenues for intervention efforts. Because of the strong negative association between severe mental distress and personal mastery, and also between HIV risk and personal mastery, approaches that enhance personal mastery are likely to have a beneficial effect on these risks as well. 
To address these issues, community organizations and social service providers should consider the value of indirect intervention approaches to reduce risks for substance use and HIV, in the promotion of health behaviors and reduction of risk such as facilitating access to transportation. Our results indicate that transportation access had a considerable positive association with high levels of personal mastery in both the bivariate and multivariate logistic regression models. Female sex workers in Miami report a lack of transportation access and note that it is a barrier to obtaining needed health and social services (Kurtz et al., 2005). Additional research has shown that lack of transportation access can be a major barrier to social service utilization and positive health outcomes (Hoerster et al., 2011; Sagrestano, Clay, Gooch, Finerman, \& Rapino, 2012), especially for African-Americans (Probst, Laditka, Wang, \& Johnson, 2007). Interventions that assist vulnerable women in accessing reliable transportation could further reduce risk and make health services utilization, including HIV testing and treatment, a more feasible practice.

The enhancement of informal and formal social support networks would likely reduce risk factors among sexual minority female sex workers. Our measure of social support included four domains: emotional/informational support, tangible support, affectionate support, and positive social interaction. Social support scores tended to be lower than national norms among patients with chronic illnesses (Sherbourne \& Stewart, 1991). This is likely due to the prevalence of social conditions of unstable housing, substance use, poverty, violence, social isolation, and disconnection from the community among this population (Surratt \& Kurtz, 2012; Surratt et al., 2011). Among sexual minority African-American women in the general population, supportive social relationships were found to be a key factor in facilitating resilience in spite of multiple structural-level social stressors such as homophobia and racism (Bowleg, Huang, Brooks, Black, \& Burkholder, 2003). For highly marginalized female sex workers, social support may be even more crucial for expressions of resilience. Findings from a risk reduction intervention study among street-based sex workers in Miami suggested that social support from peer counselors facilitated better engagement with and retention of the interventions (Surratt \& Inciardi, 2010). Similar results were found among vulnerable sexual minority African-American men (Buttram, Kurtz, \& Surratt, 2013). Thus, small efforts to address the lack of social support in any intervention are apt to have a positive impact. In addition, research has demonstrated that a lack of positive social interaction has a negative effect on the initiation of HIV care after a recent diagnosis (McCoy et al., 2009). With the increasing adoption of HIV prevention initiatives such as Treatment as Prevention (Cohen et al., 2011), this could be an important domain to include in such interventions for high-risk populations, such as street-based female sex workers. 
These results should be viewed in the context of several limitations. The data were gathered through self-report, potentially leading to underreporting of socially undesirable behaviors or reporting biases. We are confident that the use of specially trained female staff mitigated such deficiencies, though caution is warranted in interpretation. In addition, data presented here are cross-sectional, which limits our ability to make causal inferences among the key variables. Finally, though the study contained a large sample, women who participated may not have been representative of all street-based sex workers in Miami, and the findings may not be generalizable to other sex worker populations.

Despite these limitations, this study provided substantial evidence of protective factors among street-based sexual minority African-American female sex workers experiencing multiple risk factors. Responsive policies must be developed to address the lack of formal advocacy organizations that serve this marginalized and resource-poor population, and provide assistance in accessing mental and physical health care and social services. Though some organizations of this type exist in a handful of other U.S. cities, the presence of such organizations in Miami is not apparent. In addition to recommendations for intervention and public health policy, these analyses also highlight the need for additional research. Comprehensive examinations of female sex workers and other vulnerable populations should investigate social or environmental protective factors that enhance individual capacity to cope with adverse conditions that lead to better health outcomes. Such a focus on resilient behavior would produce valuable insights into the mitigation of risk factors, which would further inform intervention design, public health policy, and social service providers.

\section{ACKNOWLEDGEMENT}

The authors gratefully acknowledge Dr. James A. Inciardi, Principal Investigator of this study through 2009.

\section{FUNDING}

This research was supported by Grant Number R01DA013131 from the National Institute on Drug Abuse.

\section{REFERENCES}

Austin, S. B., Jun, H.-J., Jackson, B., Spiegelman, D., Rich -Edwards, J., Corliss, H. L., \& Wright, R. J. (2008). Disparities in child abuse victimization in lesbian, 
bisexual, and heterosexual women in the Nurses' Health Study II. Journal of Women's Health, 17(4), 597-606.

Baer, H. A., Singer, M., \& Susser, I. (1997). Medical anthropology and the world system: A critical perspective. Westport, CT: Bergin \& Garvey.

Balsam, K. F. (2003). Trauma, stress, and resilience among sexual minority women: Rising like the phoenix. Journal of Lesbian Studies, 7(4), 1-8.

Baseman, J., Ross, M., \& Williams, M. (1999). Sale of sex for drugs and drugs for sex: An economic context of sexual risk behaviors for STDs. Sexually Transmitted Diseases, 26(8), 444-449.

Bell, A. V., Ompad, D., \& Sherman, S. G. (2006). Sexual and drug risk behaviors among women who have sex with women. American Journal of Public Health, 96(6), 1066-1072.

Bohlig, E. M., \& Dennis, M. L. (1996). Development of an abbreviated symptom checklist: Preliminary analysis of the HSCL-9O in a methadone-maintenance population. Research Triangle Park, NC: Research Triangle Institute.

Bonet, L., Wells, B. E., \& Parsons, J. T. (2007). A positive look at a difficult time: A strength based examination of coming out for lesbian and bisexual women. Journal of LGBT Health Research, 3(1), 7-14.

Bowleg, L., Huang, J., Brooks, K., Black, A., \& Burkholder, G. (2003). Triple jeopardy and beyond: Multiple minority stress and resilience among Black lesbians. Journal of Lesbian Studies, 7(4), 87-108.

Burgess, D., Lee, R., Tran, A., \& Van Ryn, M. (2008). Effects of perceived discrimination and mental health services utilization among gay, lesbian, bisexual and transgendered persons. Journal of LGBT Research, 3(4), 1-14.

Buttram, M. E., Kurtz, S. P., \& Surratt, H. L. (2013). Substance use and sexual risk mediated by social support among Black men. Journal of Community Health, 38(1), 62-69.

Carlson, C. E., Chen, J., Chang, M., Batsuckh, A., Toivgoo, A., \& Riedel, M. (2012). Reducing intimate paying partner violence against women who exchange sex in Mongolia: Results from a randomized clinical trial. Journal of Interpersonal Violence, 27(10), 1311-1931.

Church, S., Henderson, M., Barnard, M., \& Hart, G. (2001). Violence by clients towards female prostitutes in different work settings: Questionnaire survey. British Medical Journal, 322(7285), 524-525.

Cochran, S. D., Ackerman, D., Mays, V. M., \& Ross, M. W. (2004). Prevalence of non-medical drug use and dependence among homosexually active men and women in the U.S. population. Addiction, 99(8), 989-998.

Cohen, M., Chen, Y., McCauley, M., Gamble, T., Hosseinipour, M., \& Kumarasamy, N. (2011). Prevention of HIV-1 infection with early antiretroviral therapy. New England Journal of Medicine, 11(365), 469-505.

Corliss, H. L., Austin, S. B., Roberts, A. L., \& Molnar, B. E. (2009). Sexual risk in "mostly heterosexual" young women: Influence of social support and caregiver mental health. Journal of Women's Health, 18(12), 2005-2010.

Coston, C. T. M., \& Ross, L. E. (1998). Criminal victimization of prostitutes: Empirical support for the lifestyle/exposure model. Journal of Crime and Justice, 21(1), 53-70.

Dalla, R. L. (2001). Et tú brutè? A qualitative analysis of streetwalking prostitutes' interpersonal support networks. Journal of Family Issues, 22(8), 1066-1085. 
Davis, N. J. (2000). From victims to survivors: Working with recovering street prostitutes. In R. Weitzer (Ed.), Sex for sale: Prostitution, pornography, and the sex industry (pp. 139-158). New York, NY: Routledge.

Dennis, M. L., Chan, Y. F., \& Funk, R. (2006). Development and validation of the GAIN short screener (GSS) for internalizing, externalizing, and substance use disorders and crime/violence problems among adolescents and adults. American Journal on Addictions, 15, 80-91.

Dennis, M. L., Titus, J. C., White, M. K., Unsicker, J. I., \& Hodgkins, D. (2002). Global Appraisal of Individual Needs - Initial (GAIN-I). Bloomington, IL: Chestnut Health Systems.

Drabble, L., Midanik, L. T., \& Trocki, K. (2005). Reports of alcohol consumption and alcohol-related problems among homosexual, bisexual, and heterosexual respondents: Results from the 2000 National Alcohol Survey. Journal of Studies on Alcobol, 66, 111-120.

Drabble, L., \& Trocki, K. (2005). Alcohol consumption, alcohol-related problems, and other substance use among lesbian and bisexual women. Journal of Lesbian Studies, 9(3), 19-30.

El-Bassel, N., Simoni, J. M., Cooper, D. K., Gilbert, L., \& Schilling, R. (2001). Sex trading and psychological distress among women on methadone. Psychology of Addictive Behaviors, 15(3), 177-184.

Farley, M., \& Barkan, H. (1998). Prostitution, violence and posttraumatic stress disorder. Women E Health, 27(3), 37-49.

Ford, C. L. (2006). Usage of "MSM" and "WSW" and the broader context of public health research. American Journal of Public Health, 96(1), 9.

Gerstorf, D., Röcke, C., \& Lachman, M. E. (2011). Antecedent-consequent relations of perceived control to health and social support: Longitudinal evidence for between-domain associations across adulthood. Journal of Gerontology: Psychological Sciences, 66B(1), 61-71.

Ghimire, L., Smith, S. W. C., van Teijlingen, E. R., Dahal, R., \& Luitel, N. P. (2011). Reasons for non-use of condoms and self-efficacy among female sex workers: A qualitative study in Nepal. BMC Women's Health, 11(42), 1-8.

Gidycz, C. A., Coble, C. N., Latham, L., \& Layman, M. J. (1993). Sexual assault experience in adulthood and prior victimization experiences: A prospective analysis. Psychology of Women Quarterly, 17(2), 151-168.

Gilbert, L., El-Bassel, N., Rajah, V., Foleno, A., \& Frye, V. (2001). Linking drug-related activities with experiences of partner violence: A focus group study of women in methadone treatment. Violence and Victims, 16(5), 517-536.

Guha, M., Baschieri, A., Bharat, S., Bhatnagar, T., Sane, S. S., \& Godbole, S. V. (2012). Risk reduction and perceived collective efficacy and community support among female sex workers in Tamil Nadu and Maharashtra, India: The importance of context. Journal of Epidemiology and Community Health, 66(Supplement 2), ii55-ii61. doi: 10.1136/jech-2011-200562

Harmell, A. L., Chattillion, E. A., Roepke, S. K., \& Mausbach, B. T. (2011). A review of the psychology of dementia caregiving: A focus on resilience factors. Current Psychiatry Reports, 13(3), 219-224.

Hillier, L., De Visser, R., Kavanagh, A. M., \& McNair, R. P. (2003). The association between licit and illicit drug use and sexuality in young Australian women. The Medical Journal of Australia, 179(6), 326-327. 
Hoerster, K. D., Mayer, J. A., Gabbard, S., Kronick, R. G., Roesch, S. C., \& Malcarne, V. L. (2011). Impact of individual-, environmental-, and policy-level factors on health care utilization among U.S. farmworkers. American Journal of Public Health, 101(4), 685-692.

Inciardi, J. A. (1995). Crack, crack house sex, and HIV risk. Archives of Sexual Behavior, 24(3), 249-269.

Inciardi, J. A., \& Surratt, H. L. (2001). Drug use, street crime and sex-trading among cocaine-dependent women: Implications for public health and criminal justice policy. Journal of Psychoactive Drugs, 33(4), 379-389.

Institute of Behavioral Research (IBR). (2006). The TCU drug screen II. Retrieved from http://ibr.tcu.edu/forms/tcu-drug-screen/

Kurtz, S. P., Surratt, H. L., Inciardi, J. A., \& Kiley, M. C. (2004). Sex work and "date" violence. Violence Against Women, 10(4), 357-385.

Kurtz, S. P., Surratt, H. L., Kiley, M. C., \& Inciardi, J. A. (2005). Barriers to health and social services for street-based sex workers. Journal of Health Care for the Poor and Underserved, 16(2), 345-361.

Li, Y., Detels, R., Lin, P., Fu, X., Deng, Z., Liu, Y., ... Wu, Z. (2010). Prevalence of Human Immunodeficiency Virus and sexually transmitted infections and associated risk factors among female sex workers in Guangdong Province, China. Journal of Acquired Immune Deficiency Syndrome, 53(Supplement 1), S48-S53.

Lindley, L. L., Barnett, H. M., \& Burcin, M. (2008). STDs among sexually active female college students: Does sexual orientation make a difference? Perspective on Sexual and Reproductive Health, 40(4), 212-217.

Maher, L. (1997). Sexed work: Gender, race and resistance in a Brooklyn drug market. New York, NY: Oxford University Press.

Mayer, K. H., Bradford, J. B., Makadon, H. J., Stall, R., Goldhammer, H., \& Landers, S. (2008). Sexual and gender minority health: What we know and what needs to be done. American Journal of Public Health, 98(6), 989-995.

McCabe, S. E., Hughes, T. L., \& Boyd, C. (2004). Substance use and misuse: Are bisexual women at greater risk? Journal of Psychoactive Drugs, 36(2), 217-225.

McCoy, S. I., Strauss, R. P., MacDonald, P. D. M., Leone, P. A., Eron, J. J., \& Miller, W. C. (2009). Social support and delays seeking care after HIV diagnosis, North Carolina, 2000-2006. AIDS Care, 21(9), 1148-1156.

Meads, C., Buckley, E., \& Sanderson, P. (2007). Ten years of lesbian health survey research in the UK West Midlands. BMC Public Health, 7(251), 1-9.

Moskowitz, J. T. (2010). Positive affect at the onset of chronic illness: Planting the seeds of resilience. In J. W. Reich, A. J. Zautra, \& J. S. Hall (Eds.), Handbook of adult resilience (pp. 465-483). New York, NY: Guilford Press.

Obrist, B., Pfeiffer, C., \& Henley, R. (2010). Multi-layered social resilience: A new approach in mitigation research. Progress in Development Studies, 10(4), 283293.

Pargament, K. I., \& Cummings, J. (2010). Anchored by faith: Religion as a resilience factor. In J. W. Reich, A. J. Zautra, \& J. S. Hall (Eds.), Handbook of adult resilience (pp. 193-210). New York, NY: Guilford Press.

Pathela, P., Blank, S., Sell, R. L., \& Schillinger, J. A. (2006). The importance of both sexual behavior and identity. American Journal of Public Health, 96(5), 765.

Pearlin, L. I., Menaghan, E. G., Lieberman, M. A., \& Mullan, J. T. (1981). The stress process. Journal of Health and Social Behavior, 22(4), 337-356. 
Pearlin, L. I., \& Schooler, C. (1978). The structure of coping. Journal of Health and Social Behavior, 19, 2-21.

Probst, J. C., Laditka, S. B., Wang, J.-Y., \& Johnson, A. O. (2007). Effects of residence and race on burden of travel for care: Cross sectional analysis of the 2001 U.S. National Household Travel Survey. BMC Health Services Research, 7(40), 1-13.

Roepke, S. K., \& Grant, I. (2011). Toward a more complete understanding of the effects of personal mastery on cardiometabolic health. Health Psychology, 30(5), 615-632.

Romero-Daza, N., Weeks, M., \& Singer, M. (2003). "Nobody gives a damn if I live or die." Experiences of violence among drug-using sex workers in Hartford, Connecticut. Medical Anthropology, 22(3), 233-259.

Romero-Daza, N., Weeks, M., \& Singer, M. (2005). Conceptualizing the impact of indirect violence on HIV risk among women involved in street-level prostitution. Aggression and Violent Behavior, 10, 153-170.

Ross, M. W., Essien, E. J., Williams, M. L., \& Fernandez-Esquer, M. E. (2003). Concordance between sexual behavior and sexual identity in street outreach samples of four racial/ethnic groups. Sexually Transmitted Diseases, 30, 110-113.

Ryan, C., Huebner, D., Diaz, R. M., \& Sanchez, J. (2009). Family rejection as a predictor of negative health outcomes in White and Latino lesbian, gay, and bisexual young adults. Pediatrics, 123(1), 346-352.

Sagrestano, L., Clay, J., Gooch, J., Finerman, R., \& Rapino, M. (2012). Examining transportation as a barrier to service utilization for PLWHA. Paper presented at the American Public Health Association, San Francisco, CA.

Saulnier, C. F., \& Miller, B. (1997). Alcohol and drug problems: Heterosexual versus lesbian and bisexual women. Canadian Journal of Human Sexuality, 6(3), 221-231.

Scheibe, A., Drame, F. M., \& Shannon, K. (2012). HIV prevention among female sex workers in Africa. Journal of Social Aspects of HIV/AIDS Research Alliance, 9(3), 167-172.

Scheier, M. F., Carver, C. S., \& Bridges, M. W. (1994). Distinguishing optimism from neuroticism (and trait anxiety, sefl-mastery, and self-esteem): A reevaluation of the Life Orientation Test. Journal of Personality and Social Psychology, 67(6), 1063-1078.

Seeman, M. (1991). Alienation and anomie. In J. P. Robinson, P. R. Shaver, \& L. S. Wrightsman (Eds.), Measures of personality and social spychological attitudes (vol. 1, pp. 292-372). San Diego, CA: Academic Press, Inc.

Shannon, K., \& Csete, J. (2010). Violence, condom negotiation, and HIV/STI risk among sex workers. Journal of the American Medical Association, 304(5), 573-574.

Shannon, K., Kerr, T., Allinott, S., Chettiar, J., Shoveller, J., \& Tyndall, M. W. (2008). Social and structural violence and power relations in mitigating HIV risk of drugusing women in survival sex work. Social Science and Medicine, 66, 911-921.

Sherbourne, C. D., \& Stewart, A. L. (1991). The MOS social support survey. Social Science and Medicine, 32(6), 705-714.

Simpson, D. D., Joe, G. W., Knight, K., Rowan-Szal, G. A., \& Gray, J. S. (2012). Texas Christian University (TCU) short forms for assessing client needs and functioning in addiction treatment. Journal of Offender Rehabilitation, 51(1-2), $34-56$. 
Spittal, P. M., Bruneau, J., Craib, K. J. P., Miller, C., Lamothe, F., \& Weber, A. E. (2003). Surviving the sex trade: A comparison of HIV risk behaviors among street-involved women in two Canadian cities who inject drugs. AIDS Care, 15(2), 187-195.

Sterk, C. E., \& Elifson, K. W. (1990). Drug-related violence and street prostitution. In M. De la Rosa, E. Y. Lambert, \& B. Gropper (Eds.), Drugs and violence: Causes, correlates, and consequences [NIDA research monograph] (vol. 103, pp. 208-221). DHHS Publication No. (ADM) 90-1721. Rockville, MD: National Institute on Drug Abuse.

Sterk, C. E., \& Elifson, K. W. (2006). Exploring sexual behaviors and sexual orientation: An ethnographic study of African American female crack cocaine users. In A. M. Omoto \& H. S. Kurtzman (Eds.), Sexual orientation and mental health (pp. 269-280). Washington, DC: American Psychological Association.

Surratt, H. L., \& Inciardi, J. A. (2004). HIV risk, seropositivity and predictors of infection among homeless and non-homeless women sex workers in Miami, Florida, USA. AIDS Care, 16(5), 594-604.

Surratt, H. L., \& Inciardi, J. A. (2010). An effective HIV risk reduction reduction protocol for drug-using women sex workers. Prevention and Intervention in the Community, 38(2), 118-131.

Surratt, H. L., Inciardi, J. A., Kurtz, S. P., \& Kiley, M. C. (2004). Sex work and drug use in a subculture of violence. Crime \& Delinquency, 50(1), 43-59.

Surratt, H. L., \& Kurtz, S. P. (2012). Foster care history and HIV infection among drug-using African American female sex workers. AIDS and Behavior, 16(4), 982-989.

Surratt, H. L., Kurtz, S. P., Chen, M., \& Mooss, A. (2011). HIV risk among female sex workers in Miami: The impact of violent victimization and untreated mental illness. AIDS Care, 24(5), 553-561.

Surratt, H. L., Kurtz, S. P., Weaver, J. C., \& Inciardi, J. A. (2005). The connections of mental health problems, violent life experiences, and the social milieu of the "stroll" with the HIV risk behaviors of female street sex workers. Journal of Psychology and Human Sexuality, 17(1/2), 23-44.

Titus, J. C., Dennis, M. L., White, W. L., Scott, C. K., \& Funk, R. R. (2003). Gender differences in victimization severity and outcomes among adolescents treated for substance abuse. Child Maltreatment, 8(1), 19-35.

Tucker, J. S., Ellickson, P. L., \& Klein, D. J. (2008). Understanding differences in substance use among bisexual and heterosexual young women. Women's Health Issues, 18(5), 387-398.

Ungar, M. (2008). Resilience across cultures. British Journal of Social Work, 38, 218-235.

Waters, J. K., \& Biernacki, P. (1989). Targeted sampling: Options for the study of hidden populations. Social Problems, 36(4), 416-430.

Weiner, A. (1996). Understanding the social needs of streetwalking prostitutes. Social Work, 41(1), 97-105.

Wenzel, S. L., Leake, B. D., \& Gelberg, L. (2001). Risk factors for major violence among homeless women. Journal of Interpersonal Violence, 16(8), 739752.

Wilsnack, S. C., Hughes, T. L., Johnson, T. P., Bostwick, W. B., Szalacha, L. A., Benson, P., ... Kinnison, K. E. (2008). Drinking and drinking-related problems 
among heterosexual and sexual minority women. Journal of Studies on Alcohol and Drugs, 69, 129-139.

Young, R. M., \& Meyer, I. H. (2005). The trouble with "MSM" and "WSW": Erasure of the sexual-minority person in public health discourse. American Journal of Public Health, 95, 1144-1149.

Younger, J. B. (1991). A theory of mastery. Advances in Nursing Science, 14(1), 76-89.

Yuen, W. W., Wong, W. C., Tang, C. S., Holroyd, E., Tiwari, A. F., Fong, D. Y., \& Chin, W. Y. (2013). Evaluating the effectiveness of Personal Resilience and Enrichment Programme (PREP) for HIV prevention among female sex workers: A randomised controlled trial. BMC Public Health, 13, 683. 